\title{
Bilateral Posterior Ischemic Optic Neuropathy in a Patient with Severe Diabetic Ketoacidosis
}

\author{
Albert E. Smolyar ${ }^{\mathrm{a}}$ Pedram Hamrah ${ }^{\mathrm{b}}$

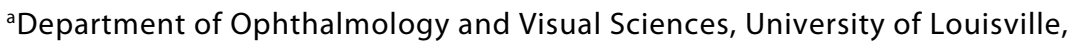 \\ Louisville, Ky., and ' ${ }^{\mathrm{b}}$ Massachusetts Eye and Ear Infirmary, and Department of \\ Ophthalmology, Harvard Medical School, Boston, Mass., USA
}

\section{Key Words}

Diabetes $\cdot$ Ketoacidosis $\cdot$ Neuropathy $\cdot$ Posterior ischemic optic neuropathy

\begin{abstract}
Purpose: To report a case of bilateral posterior ischemic optic neuropathy (PION) in a patient with severe diabetic ketoacidosis (DKA).

Design: Observational case report.

Participant: A 35-year-old male who suffered bilateral visual loss during a severe episode of DKA.

Methods: Neuro-ophthalmological examination, neuroimaging consisting of a CT scan and MRI of the brain and orbits, as well as a MRA of brain vessels.

Results: Bilateral PION was diagnosed in a 35-year-old male with no light perception vision, who emerged from a coma caused by severe DKA. The patient developed optic nerve pallor in both eyes 4 weeks after the initial examination. Visual acuity with no light perception in both eyes remained unchanged after 6 months' follow-up.
\end{abstract}

Conclusions: Severe DKA can be complicated by bilateral PION, resulting in total blindness.

\section{Introduction}

Posterior ischemic optic neuropathy (PION) is a rare disorder. It can affect patients of all ages and often manifests as sudden-onset visual loss with possible bilateral involvement. Clinical settings associated with PION include severe perioperative hypotension and anemia [1-3]; systemic vascular disorders, including giant cell arteritis, carotid dissection, Takayasu arteritis, systemic lupus erythematosus, sickle cell disease and migraines; hemodialysis treatment, as well as several neoplastic and infectious causes. 
Here, we report a case of bilateral PION following diabetic ketoacidosis (DKA) leading to bilateral blindness.

\section{Case Report}

A 35-year-old white male was found unresponsive several days after discontinuing his insulin injections, with vomiting and diarrhea that followed binge drinking. His past medical history was significant for longstanding, uncontrolled type 1 diabetes mellitus. At the time of admission, the patient had a body temperature of $30^{\circ} \mathrm{C}$, blood pressure of $66 / 36 \mathrm{~mm} \mathrm{Hg}$, blood $\mathrm{pH}$ of 6.82 and blood glucose of $1,107 \mathrm{mg} / \mathrm{dl}$ Toxicology screening, including blood alcohol level, was negative. In addition, electrocardiography demonstrated a junctional heart rhythm. The patient was further noted to have bilateral sluggish pupils.

DKA, rhabdomyolysis, and acute renal and respiratory failure were diagnosed at this time. The patient was then intubated, hydrated with IV fluids and treated aggressively with an insulin drip and sodium bicarbonate. His DKA and renal failure resolved over the course of the next few days.

Neuroimaging studies including CT scan, MRI and MRA of the brain were performed during this time and were all within normal limits. Following extubation 1 week after admission, the patient was noted to behave like a blind person, with amaurotic pupils observed bilaterally.

Initial ophthalmologic examination revealed no light perception vision in both eyes. His pupils were round and symmetric at $6 \mathrm{~mm}$, but were not reactive to light. On slit lamp examination, the anterior segment was found to be within normal limits. Dilated fundus exam revealed mild nonproliferative diabetic retinopathy in both eyes. The optic nerve discs appeared normal with no sign of swelling or atrophy. The patient denied consumption of any toxic substances other than alcohol-containing beverages. His eye exam at 1 month' and 6 months' follow-up remained unchanged, except for progressive bilateral optic nerve disc pallor (ig. 1).

\section{Discussion}

The patient was diagnosed with bilateral PION based on the fact that his optic nerves were normal on presentation, along with no light perception vision and pupils that were nonreactive to light, as well as the development of optic nerve atrophy during the 4 weeks following the episode of DKA. Our diagnosis was further supported by normal results of the neuroimaging studies and the lack of additional identifiable reasons for the visual loss.

DKA is a serious complication of diabetes mellitus, leading to significant morbidity and mortality. Ophthalmic complications resulting from DKA are rare. Only a few cases of optic atrophy associated with DKA have been reported so far. In 1 case, a patient developed nonarteritic anterior ischemic optic neuropathy (NAAION) following severe gastrointestinal hemorrhage resulting in myocardial and cerebral infarction complicated by DKA [4], where the NAAION was attributed to hypotension. Another case reported a patient who developed optic atrophy following acute cerebral encephalopathy, cerebral edema and DKA [5]. Finally, a third case reported a patient with bilateral simultaneous NAAION associated with DKA and hypotension, where the ischemic neuropathy was thought to be due to the hypotension [6]. In addition, Bertram et al. [7] reported bilateral PION with onset of visual loss 2 weeks prior to an episode of DKA.

The retrobulbar segment of the optic nerve is only supplied by the circumferential pial capillary plexus derived from collateral distal branches of the ophthalmic artery that surrounds it, as opposed to the anterior portion of the optic nerve that is supplied both by the pial plexus and the central retinal artery [8]. The central portion of the retrobulbar 
optic nerve is poorly vascularized, and penetrated by only a small number of capillaries that are not capable of autoregulatory control, putting it at risk for ischemia during periods of systemic hypotension and anemia. One of the postulated mechanisms of PION, therefore, is a compression of pial vessels of the orbital optic nerve due to hypoxic edema associated with systemic hypotension [9]. It is believed that certain patients have optic nerves that are more susceptible to hypotension, possibly due to a retrovascular border zone or watershed area.

In the patient described herein, DKA was accompanied by profound hypotension, which is believed to have perhaps been the main cause of PION. It is possible that severe metabolic derangement also contributed to the development of PION in this patient. Optic nerve atrophy has been previously reported in association with various metabolic disturbances, including propionic acidemia, Wolfram (DIDMOAD) syndrome, Leigh disease and other disorders. However, the exact mechanism of metabolic damage to the optic nerve has not yet been elucidated. Yanagawa et al. [10] reported a case of reversible blindness in a patient with alcoholic ketoacidosis. They suggested that the visual loss could be related to an impairment of the neural transmission at the level of the retina due to severe acidosis, although it is not clear whether the patient they described suffered from retinal damage or from optic neuropathy. Long-term follow-up data was not provided in their case.

To our knowledge, this is the first reported case of severe bilateral PION associated with DKA resulting in total blindness; it adds to the growing list of retinal and optic nerve complications associated with diabetes and particularly DKA. Both primary care providers and ophthalmologists should be aware of the possibility of PION as a result of DKA. Prompt correction of both metabolic abnormalities and hypotension, if present, may be instrumental in decreasing the risk of devastating visual loss.

\section{Acknowledgement}

We would like to thank Dr. Alfredo A. Sadun from the Departments of Ophthalmology and Neurosurgery, Keck School of Medicine of USC and the Doheny Eye Institute, Los Angeles, Calif., USA, for his critical review of the manuscript.

\section{Disclosure Statement}

The authors have no conflict of interest. 


\begin{tabular}{l|l|l|l} 
Case Reports in & $\begin{array}{l}\text { Case Rep Ophthalmol 2011;2:91-94 } \\
\text { DOI: 10.1159/000325141 }\end{array}$ & $\begin{array}{l}\text { Published online: } \\
\text { February 25, 2011 }\end{array}$ & $\begin{array}{l}\text { ○ 2011 S. Karger AG, Basel } \\
\text { ISSN 1663-2699 } \\
\text { www.karger.com/cop }\end{array}$ \\
\hline
\end{tabular}
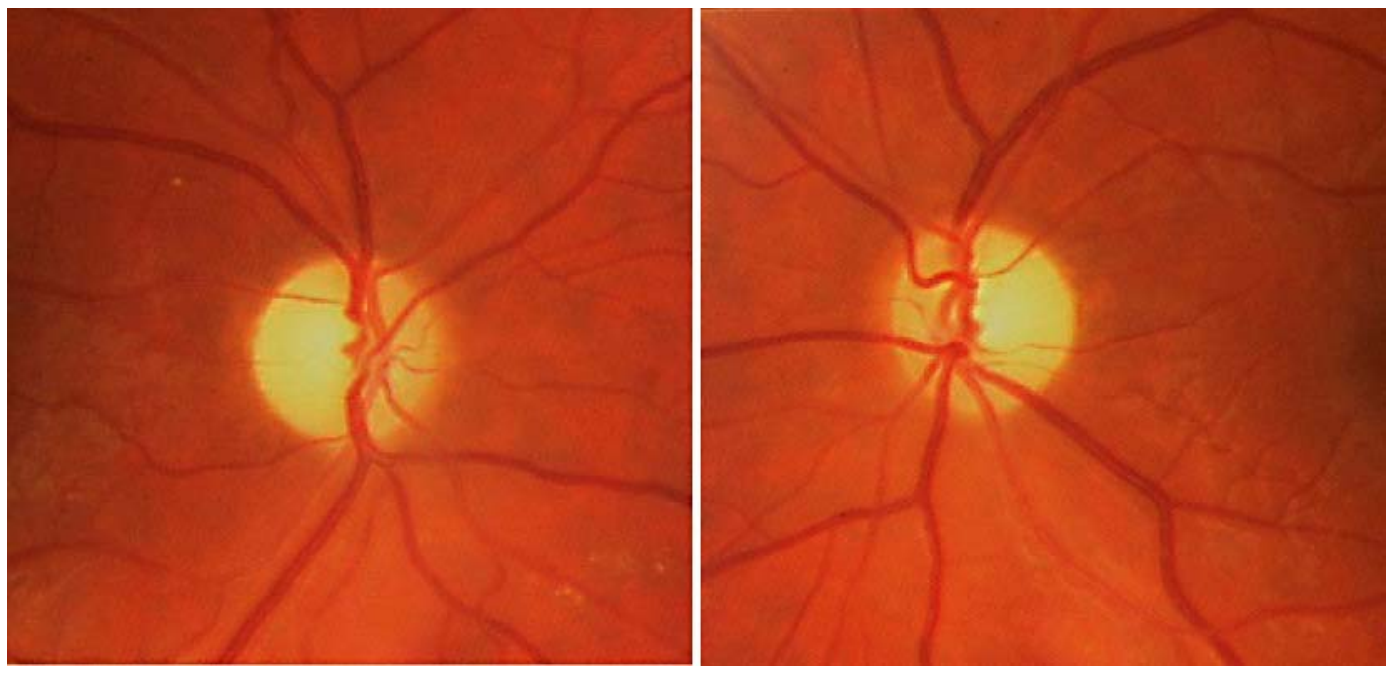

Fig. 1. Fundus examination performed 1 month after the visual loss revealed diffuse pallor of both optic discs, OD (right) and OS (left).

\section{References}

1 Sadda SR, Nee M, Miller NR, et al: Clinical spectrum of posterior ischemic optic neuropathy. Am J Ophthalmol 2001;132:743-750.

2 Alexandrakis G, Lam BL: Bilateral posterior ischemic optic neuropathy after spine surgery. Am J Ophthalmol 1999;127:354-355.

3 Rizzo JF 3rd, Lessel S: Posterior ischemic optic neuropathy during general surgery. Am J Ophthalmol 1987;103:808-811.

4 Rootman J, Butler D: Ischaemic optic neuropathy - a combined mechanism. Br J Ophthalmol 1980;64:826831.

-5 Lufkin EG, Reagan TJ, Doan DH, Yanagihara T: Acute cerebral dysfunction in diabetic ketoacidosis: survival followed by panhypopituitarism. Br J Ophthalmol 1977;26:363-369.

6 Song SH, Mowbray A, O’Shea H, Campbell IW: Bilateral optic atrophy following diabetic ketoacidosis. Diabet Med 2000;17:394-396.

7 Bertram B, Reim H, Reim M: Bilateral posterior ischemic optic neuritis in an adolescent with diabetes mellitus with decompensated blood glucose homeostasis (in German). Klin Monatsbl Augenheilkd 1995;206:39-45.

8 Isayama Y, Hiramatsu K, Asakura S, Takahashi T: Posterior ischemic optic neuropathy. I. Blood supply of the optic nerve. Ophthalmologica 1983;186:197-203.

-9 Hayreh SS: Posterior ischemic optic neuropathy. Ophthalmologica 1981;182:29-41.

10 Yanagawa Y, Kiyozumi T, Hatanaka K, et al: Reversible blindness associated with alcoholic ketoacidosis. Am J Ophthalmol 2004;137:775-777. 